\title{
Egg Cluster Characteristics of Fall Armyworm, Spodoptera frugiperda (Lepidoptera: Noctuidea) in Sri Lanka under Laboratory Conditions
}

\author{
R.H. Kasige ${ }^{1}$, C.D. Dangalle ${ }^{1 *}$, N. Pallewatta ${ }^{1}$ and M.T.M.D.R. Perera ${ }^{2}$ \\ Received: 09 ${ }^{\text {th }}$ December 2020 / Accepted: 10 $0^{\text {th }}$ November 2021
}

\begin{abstract}
Purpose: Spodoptera frugiperda is a recently introduced alien invasive pest in Sri Lanka which can be a threat to many crops including maize, paddy, sugarcane, green gram, vegetables and fruits. Identification of this pest at the egg stage is important in controlling the larval stages of development. Therefore, the present study was conducted to record the morphological and morphometric characters of the eggs of S. frugiperda for accurate identification at the initial stage.

Research Method: Thirty-six egg masses of laboratory reared S. frugiperda were observed and measured under a dissecting microscope. Position of the egg clusters on plant, characters of the egg cluster and eggs, number of eggs per egg cluster and diameter of eggs were recorded.

Findings: The study revealed that the female S. frugiperda laid eggs mainly on the underside of the leaf blade as clusters containing $9-200$ (73 \pm 7$)$ eggs. Eggs were mostly arranged as single layers and when arranged in multiple layers, the bottom layer had a larger number of eggs than the upper layers. Most of the egg clusters were irregular in shape and some were covered with hairs. Eggs were spherical and initially creamy white in colour that gradually turned light grey when about to hatch. The diameter of eggs ranged from $0.38 \mathrm{~mm}$ to $0.55 \mathrm{~mm}$.

Originality/value: The study documents the morphological and morphometric characters of S. frugiperda eggs for accurate identification. Early detection of the insect pest facilitates the management of their population before causing an economic damage.
\end{abstract}

Keywords: Egg cluster, Morphology, Morphometrics, Spodoptera frugiperda, Sri Lanka

\section{INTRODUCTION}

The Fall Armyworm, Spodoptera frugiperda (J.E. Smith) is a lepidopteran polyphagous pest native to tropical and subtropical America (De Groote et al., 2020). It is a serious pest of over 80 crop plant species including maize, sorghum, beans, cotton, wheat, potato, soybean, cowpea, peanuts, sugarcane and vegetables (Sisay et al., 2018; Assefa and Ayalew, 2019; Tambo et al., 2020). The Fall Armyworm destroys young crop plants by attacking their growing points, and burrows into cobs of older plants adversely affecting the yield quality and quantity (Tambo et al., 2020). Due to its broad host range and longdistance migration capability, $S$. frugiperda has spread from the Western part of the world to the Eastern part, and has caused large infestations in southern China, Myanmar and India threatening the rice and millet crop cultivations (Nagoshi et al., 2020).

Spodoptera frugiperda has been a problematic species in Sri Lanka since 2018, causing a significant damage to maize, cereals, grass species and other important agricultural crops (Early et

\footnotetext{
${ }^{I^{*}}$ Department of Zoology and Environment Sciences, University of Colombo, Sri Lanka.

cddangalle@zoology.cmb.ac.lk

${ }^{2}$ Plant Quarantine Unit, Gannoruwa, Peradeniya, Sri Lanka.

(D)https://orcid.org/0000-0002-0882-7147
} 
al., 2018). The insect is currently considered as an alien invasive pest, and has caused considerable damage to maize in the Uva province which has the highest land extent used for maize cultivation. $11.3 \%$ of the land area used for maize cultivation in the Ratnapura district has also been infested with $S$. frugiperda, and field surveys reveal that the pest can be devastating to paddy cultivations in the future (Perera et al., 2019). $S$. frugiperda attacks on sugarcane plantations have also been reported from Sevanagala, Pelwatte, Udawalawe, Siyambalanduwa and Hingurana areas of Sri Lanka (Wanasinghe et al., 2019), and according to Wijerathna et al. (2021), although $S$. frugiperda displays the highest host preference to maize, it can use vegeTable 0crops as alternative hosts for oviposition in the absence of maize. Thus, S. frugiperda has directly affected the agriculture sector of the country resulting in a huge economic loss mainly in maize production and has threatened the country's food and nutritional security, and livelihood of farmers and corn vendors causing a detrimental effect on their social well-being. It has also affected the livestock sector due to transport ban hold on corn plants to prevent $S$. frugiperda dispersal.

One of the most important factors that help the spread of $S$. frugiperda is its ability to produce a large number of eggs (De Groote et al., 2020). The adult females deposit a cluster of eggs with a few hundred eggs, usually on the underside of the leaves (Harrison et al., 2019). The abaxial surface of the leaves are considered as the site preferred by $S$. frugiperda for oviposition, and egg masses are usually not observed in other plant parts such as the bracts, flower buds, flowers and bolls (Junior et al., 2013). Egg mass cluster frequency per plant, egg numbers per cluster, morphological and morphometric features of eggs have not revealed to be different amongst $S$. frugiperda occupying different geographical regions. However, changes in the average number of egg masses per plant and egg numbers per cluster have shown small but significant changes according to the host plant. According to Sotelo-Cardona et al. (2021), S. frugiperda egg mass clusters and eggs per cluster is the highest on maize plants while infestations are not found on tomato plants. This host plant preference has also been observed by Murua et al. (2008), irrespective of the fact that the records have been collected from different geographical regions in Argentina.

Control of insect pest species by destruction of the egg stage is considered as a first lineof-defense in insect pest management as this lessens the development of the harmful larval and adult stages and prevents the infestation of parasitic insects that maybe be attracted to the eggs. Species of Hymenoptera are known to be effective as egg parasitoids for the biological control of S. frugiperda (Tefera et al., 2019), and there are many predators that attack the eggs of this species (Hardke et al., 2015). However, for successful management, the eggs of $S$. frugiperda must be distinctly identified from the eggs of the beneficial insects, and the locations that the eggs are deposited accurately identified (Campbell et al., 2016).

In most studies of $S$. frugiperda, egg stages have been examined mainly on the basis of morphological characters such as colour and structural characteristics (texture, chorion architecture) (Santillán-Guayasamín et al., 2017). Use of morphometric characters are limited, but essential, as the egg stages in the species that belong to genus Spodoptera have many similar characteristics which require both morphological and morphometric variables for identification.

Therefore, the present study was undertaken to characterize the egg stage of $S$. frugiperda of Sri Lanka using morphological and morphometric analysis.

\section{MATERIALS AND METHODS}

\section{Sample collection and laboratory rearing}

Spodoptera frugiperda larvae were collected during January to October 2019 from maize fields in four locations - Mahailuppallama, Anuradhapura district, North-Central province; Polpithigama, Kurunegala district, NorthWestern province; Meegahakiula, Badulla district, Uva province; Rideemaliyadde, Badulla district, Uva province. The larvae were cultured in the insectary facilities of the Department of 
Zoology and Environment Sciences, University of Colombo, under $28 \pm 2{ }^{\circ} \mathrm{C}$ temperature, 80 $\pm 10 \%$ relative humidity and a $12 \mathrm{~h}: 12 \mathrm{~h}$ light: dark natural photoperiod. The cultures were maintained on $3-4$ week age maize plants in plastic pots. The emerged adult moths were moved to standard insect rearing cages $(66 \times 66$ $x 78 \mathrm{~cm}^{3}$ ) and were given a food source of $50 \%$ bee-honey and 50\% water (bee-honey: water 1:1) and were provided with $30 \mathrm{~cm}$ height potted maize plants for oviposition. The moths were introduced to cages in 1: 3 male to female ratio.

Egg clusters were collected from plants after 3-4 days of introducing the adults to the cage.

\section{Morphological and morphometric characterization of $S$. frugiperda eggs}

A total of 36 egg clusters obtained from the adults of the larvae collected from the four locations were used collectively for the study. The first egg cluster was collected in early June 2019, while the last or $36^{\text {th }}$ egg cluster was collected in mid-September 2019. Observations were made using the dissecting microscope / Zoom Stereo Microscope (OLYMPUS SZ51, Japan).

Several attributes of $S$. frugiperda eggs including the position of the egg cluster on the plant, shape of the egg cluster, number of eggs per egg cluster (clutch size), colour of eggs (using a Munsell colour chart), shape and arrangement of eggs within the egg cluster and other special observable features were recorded. The average diameter of an egg was measured using a graticule placed in the eye piece of the dissecting microscope. The characteristics of eggs were recorded using digital photographs, drawings and written descriptions.

Eggs were checked daily to record newly emerged larvae, colour changes of egg and incubation period.

\section{RESULTS AND DISCUSSION}

\section{Position of egg cluster on the plant}

Mature and gravid adult S. frugiperda female moths laid eggs in clusters/egg masses usually at night. They laid eggs more than once per life time at different positions of the plants. Egg clusters were mostly found on the underside of the leaf blade (abaxial) of maize $(61.11 \%)$ but there were instances where egg clusters were present on the upper side of the leaf blade (adaxial) (13.89\%), near the base of the plant close to the leaf nodes $(5.56 \%)$ and rarely on the wall of the plastic moth rearing cages $(2.78 \%)$. Most egg clusters were found near the mid rib and the leaf margin on the underside of the maize leaf blade $(61.11 \%)$ (Figure 01).

The eggs are the first life stage of most insects that are directly exposed to the environment and to predators, parasitoids and abiotic stresses (Hilker and Fatouros, 2015). Further, egg laying site selection is important in providing an adequate place for the subsequent success of larval development (Storey-Palma et al., 2014). Therefore, many Lepidopteran insects such as the leaf miner, Angelabella tecomae, the Bertha armyworm, Mamestra configurata and the Beet armyworm, Spodoptera exigua, lay eggs on the underside of host plant leaves, where eggs and the emerging larvae are protected from high temperatures, sunlight, wind, predators and parasitoids (Ulmer et al., 2003; Azidah and Sofian-Azirun, 2006; Storey-Palma et al., 2014) . However, the majority of Lepidoptera lay eggs singly and the larvae develop solitarily (Stamp, 1980; Hebert, 1983; Ulmer et al., 2003). Laying eggs singly is considered the ancestral state and the proportion of Lepidoptera retaining this strategy suggests that laying eggs singly is generally advantageous because of the reduced competition from conspecifics for food (Ulmer et al., 2003). However, certain Lepidoptera lay their eggs in clusters indicating that under certain circumstances this may be more beneficial. 

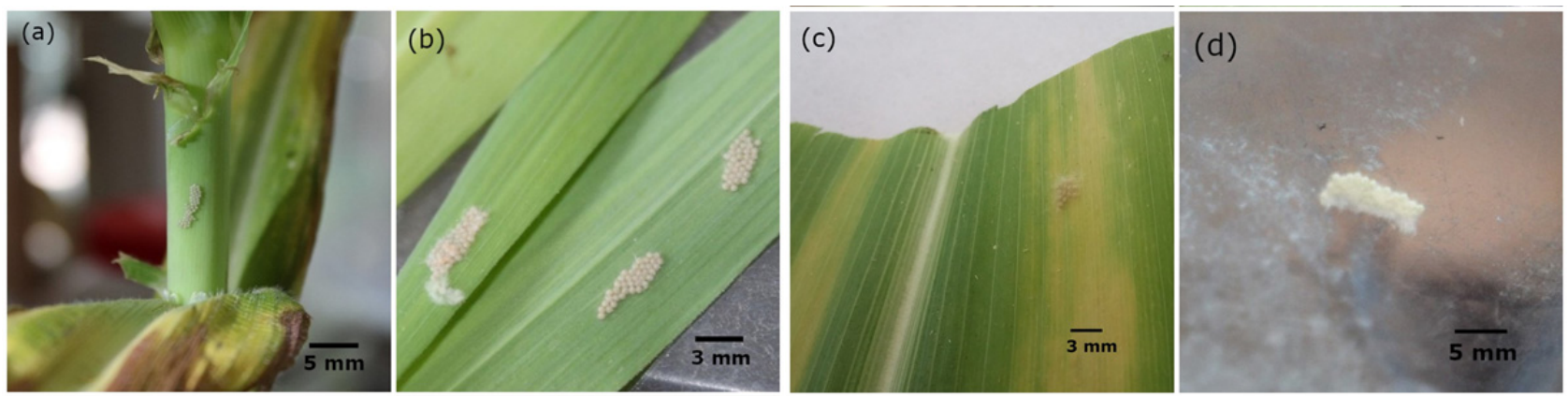

Figure 01: Different positions where egg masses were laid. (a) Leaf nodes of the plant (b) Underside of the leaf blade (c) Upper side of the leaf blade (d) Wall of the plastic moth rearing cage

\section{Characters of the egg clusters}

The female $S$. frugiperda laid eggs as clusters that were mostly irregular in shape but some were circular and rectangular. The eggs were tightly attached to the substrate, packed and arranged in rows resembling a chain of pearls /string of beads. The eggs were sometimes deposited in multiple layers but most eggs were spread over a single layer attached to foliage. The highest percentage; $72.22 \%$, of total observed egg clusters were single layered while $27.77 \%$ were multiple layered. The egg masses were flat when arranged in a single layer. When having two or more layers, the bottom layer contained a larger number of eggs compared to the top layer / layers (Figure 02).
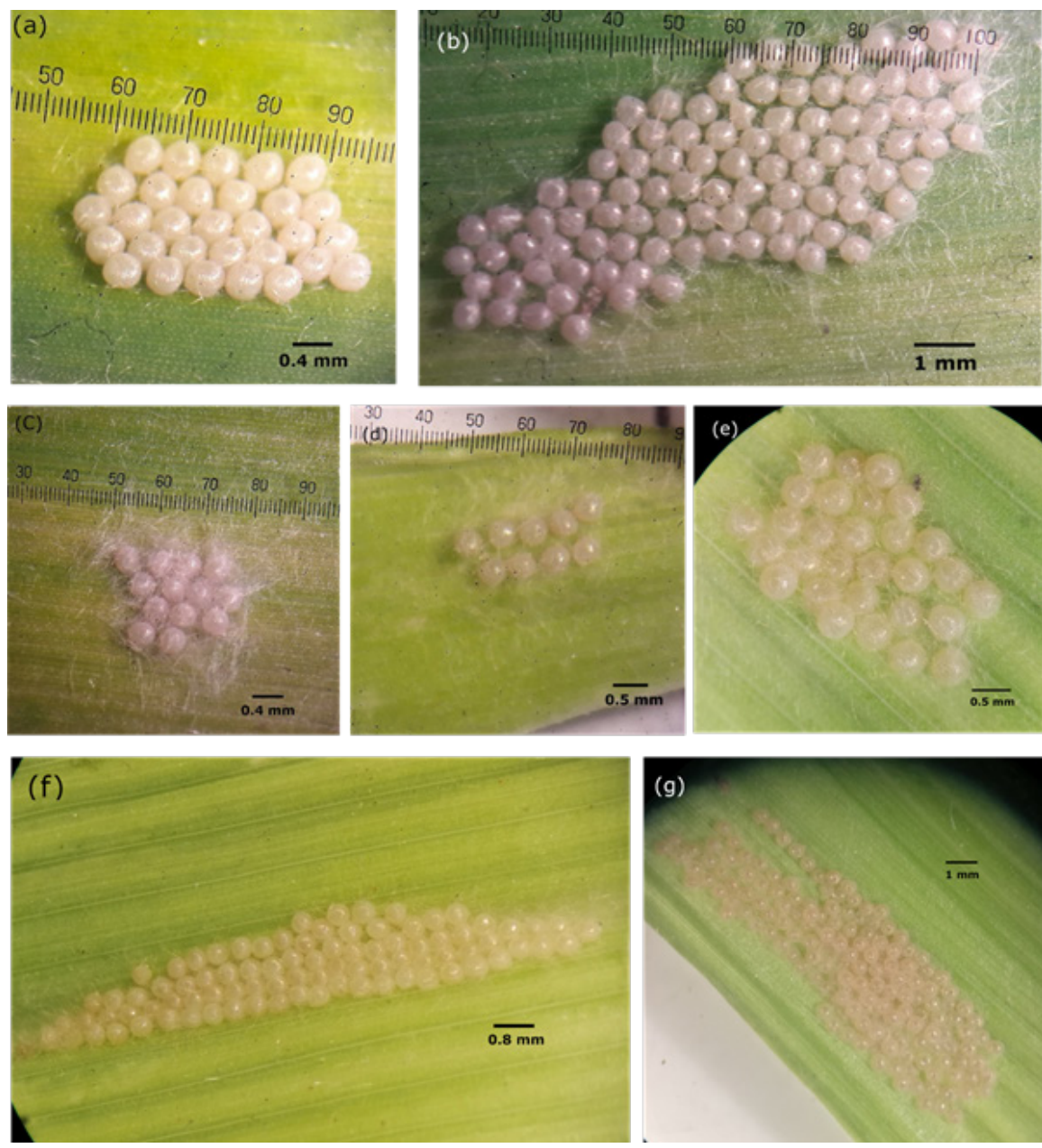

Figure 02: $\quad$ Shape and arrangement of egg masses (a) - (f) Single layered; (g) Multiple layered 
The strategy of egg clustering may hold advantages for the eggs by protecting them from desiccation and other environmental factors as well as parasites and predators (Ulmer et al., 2003). Single eggs are more likely to be attacked by predators who are more strongly deterred from attacking clusters than single eggs (Agarwala and Dixon, 1993). Bessera and Parra (2005) have demonstrated that having multiple layers of eggs tend to reduce the level of parasitism. The Hymenopteran parasitoid, Trichogramma atopovirila, parasitizing $S$. frugiperda eggs, showed reduced percentages of parasitism when the number of layers in the egg cluster increased. Insect eggs require exchange of gases for respiration and this is achieved via tiny pores located on the egg shell (Campbell et al., 2016). Exchange of gases will be more efficient if eggs are exposed to environment and may explain the strategy for single layering of eggs in S. frugiperda. Hair-like strands covering the egg clusters of $S$. frugiperda and the ridge-like structures present on their eggs may compensate for their exposure to the environment. Detailed sculpturing on the outside of the eggshell is known to protect insect eggs from environmental stress and provides a barrier against insecticide penetration (Campbell et al., 2016).

In the present study, some egg clusters were covered with white/ grey hair-like strands secreted by the anal region of the female moths. In Lepidoptera, most species of Noctuidae cover their egg masses with secretions, hair-like strands or discarded scales (Peterson, 1964), and many species of Spodoptera appear to have morphologically similar egg masses covered with hair strands (Korycinska, 2012). According to a study conducted by Temerak (2006), egg masses of the Cotton Leaf Worm, Spodoptera littoralis, are either naked or partially covered or fully covered with a ratio of 10:2:1 respectively, with only a low percentage of egg masses being fully covered. A similar observation was also revealed in the present study, in which the egg masses that were fully covered represented the lowest percentage (11.11\%). However, according to the current study, in S. frugiperda, the naked to partially covered egg masses were more or less similar in frequency accounting for $41.66 \%$ and $47.22 \%(1: 1)$ of the total egg mass respectively (Figure 03). S. frugiperda may cover their egg masses with hairs for various reasons such as unfavourable environmental conditions and protection from natural enemies such as predators and parasitoids. Dong et al. (2021) revealed that the proportion of parasitism by egg parasitoids of $S$. frugiperda was lower on covered egg masses when compared with naked egg masses. Further, according to Temerak (2006), the performance of an insecticide on naked egg masses of Spodoptera littoralis was faster and greater than on full covered egg masses. Therefore, when conducting pest control strategies against $S$. frugiperda, chemically or biologically, it is exceedingly important to consider the appearance of egg masses and use chemicals that will suffice effective control or use parasitoid species that will not be affected by the coverings of the egg masses.

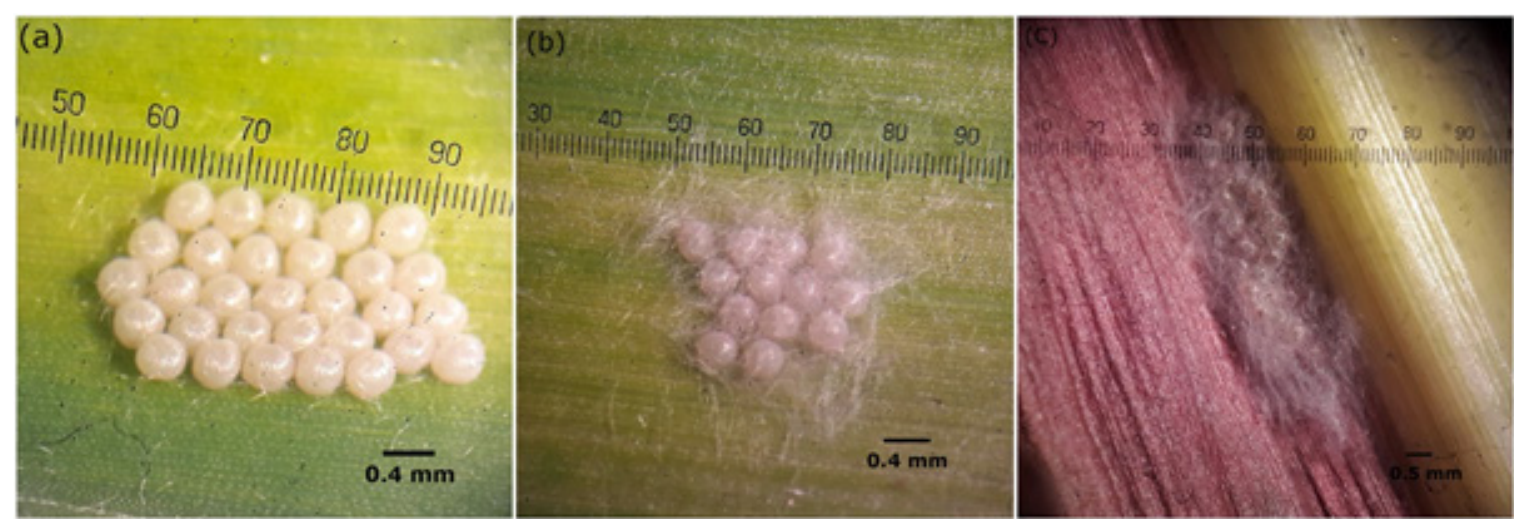

Figure 03: Appearance of egg masses (a) Naked (b) Partially covered with hairs (c) Fully covered with hairs 


\section{Morphology of eggs}

The eggs were small with a shiny egg shell and had a uniform colour with no pigmentation. The colour varied from cream colour / pale yellow / pearl-white to light grey with egg maturity. They were whitish creamy colour as soon as they were laid and turned to light grey colour when they were about to hatch. The larval head was observable in greatly enlarged eggs which were about to hatch.

When considering the shape of a single egg, it was spherical in shape and had a rounded shape in dorsal view. Eggs were heavily sculptured and distinct ridges were observed from the apex to the base of the egg shell when observed under higher magnification $(\mathrm{x} 40)$. The ridges were horizontally connected to each other (Figure 04).

\section{Morphometry of eggs}

A total of 53 female insects collectively produced 203 egg clusters during the study period. The duration of the egg stage varied from 3-4 $( \pm 0.09)$ days.
The number of eggs per egg cluster (clutch size) varied under laboratory conditions. The clutch size ranged from $9-200$ eggs per cluster, with an average of $73( \pm 7)$ eggs. The diameter of the eggs in a given egg cluster varied with an average ranging from $0.38 \mathrm{~mm}$ to $0.55 \mathrm{~mm}$. The mean diameter of an egg was recorded as $0.43 \pm 0.04$ $\mathrm{mm}$ (Figure 05).

The average diameter of an egg was similar to the diameter reported by Capinera (2000), who observed a value of $0.43 \mathrm{~mm}$. The diameter of the egg stage depends predominantly on the temperature and humidity of the external environment (Luginbill, 1928). In the present study, eggs hatched in 3-4 days under laboratory settings, while other studies have reported it as 3 days (Hinds and Dew, 1915; Luginbill, 1928; Murúa and Virla, 2004) and as a range of 3-4 days (when temperature is $70-80{ }^{\circ} \mathrm{F}$ ) by Sparks (1979). These variations could be due to different plant varieties, differences in phytochemicals produced by the plant varieties and external environmental conditions (Vargas-Madríz et al., 2013).

The varietal differences may have affected the size of the eggs and contributed to individual variations in egg morphometrics.
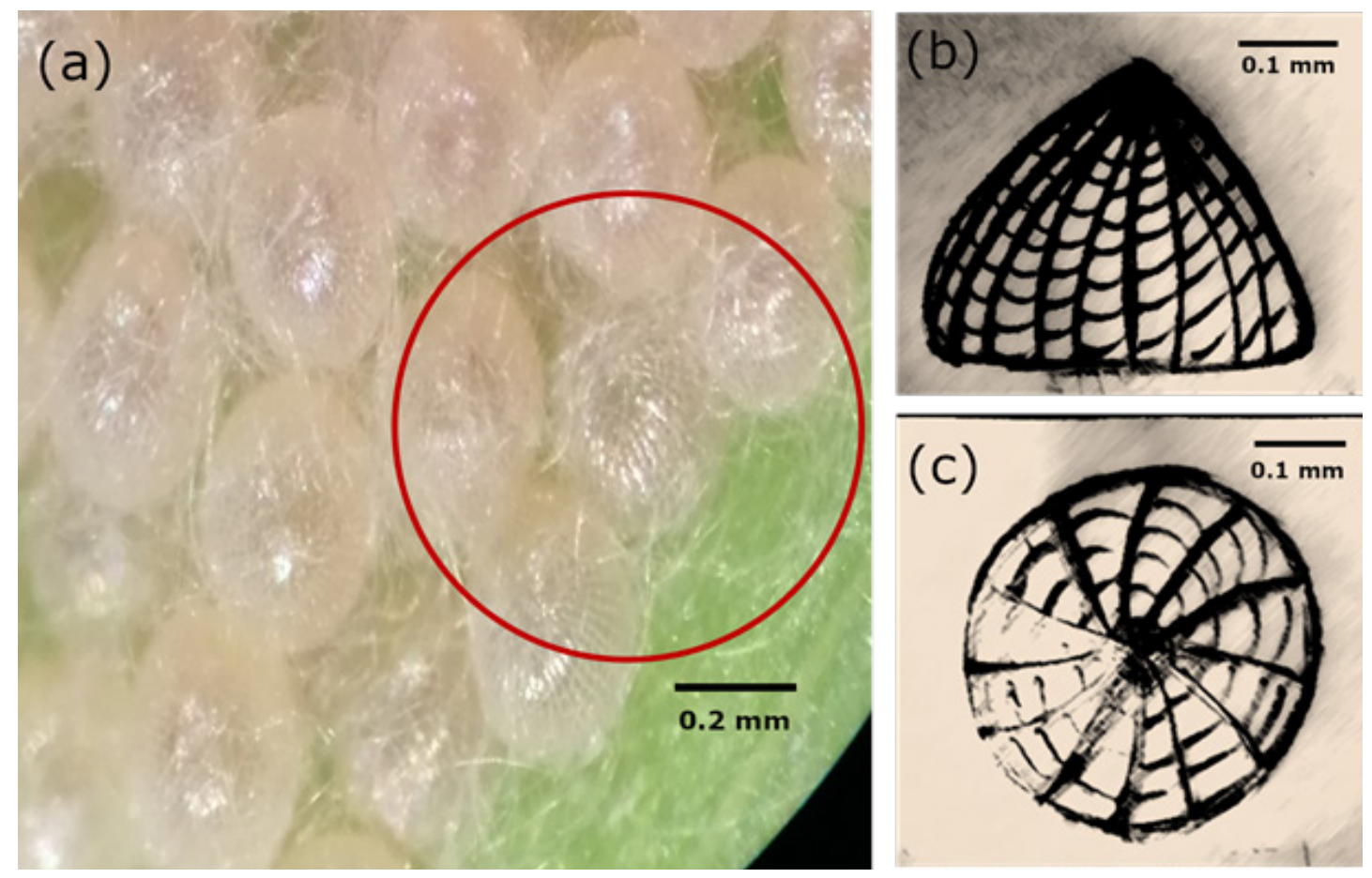

Figure 04: Sculpturing of eggs (a) the ridges present in eggs (b) lateral view showing the ridges from apex to base of egg (c) dorsal view showing the horizontal connections between egg ridges 




Figure 05: Histogram showing the average egg diameter per egg mass for the 36 egg clusters observed in the study

Undergoing colour change during the incubation period, sculpture on the egg shell, hairlike covering of egg clusters are characters unique to Lepidopterans of family Noctuidae (Peterson, 1964). Such characters are known to have developed insecticide resistance in eggs (Campbell et al., 2016), and resistance to chemicals in $S$. frugiperda have often resulted in pest resurgence (Assefa and Ayalew, 2019). However, control of $S$. frugiperda when in the egg stage is more effective as larvae migrate into the plant whorl immediately after its emergence and remain sheltered during the whole larval phase inflicting a serious downside to insecticide spraying (Bialozor et al., 2020). Small-holder farmers of many countries carry out handpicking and crushing of egg masses of $S$. frugiperda, especially as the method is cheap and it only requires readily available material (Ahissou et al., 2021; Njuguna et al., 2021). Chemical extracts of Neem (Azadirachta indica) have been found to have high ovicidal activity on $S$. frugiperda egg masses less than 48 hours of age (Paredes-Sánchez et al., 2021). Further, many biological control practices have been conducted using various species of egg parasitoids (Beserra and Parra, 2005; Temerak, 2006; Liao et al., 2019; JaraleñoTeniente et al., 2020; Dong et al., 2021; ParedesSánchez et al., 2021). However, for the success of these control practices, accurate information on $S$. frugiperda eggs is essential and knowledge on their locations on plants, characters, strengths and weaknesses is required. The present study intends to provide the much needed knowledge on $S$. frugiperda egg characters which may be useful in developing control strategies. However, studies conducted using field conditions are also required in order to determine any changes in egg characters influenced by environmental factors of the sampling site and diet of female adult moths.

\section{CONCLUSIONS}

Spodoptera frugiperda may remain a significant challenge for the foreseeable future and effective management strategies are required. Physical, chemical and biological control of egg masses of the pest is widely used by farmers as a first line of defense as this lessens the development of the more harmful larval stages. However, effective control of egg masses rely upon the accurate detection, identification and understanding of the defensive characteristics of the Spodoptera frugiperda eggs. The current study intended to enhance the knowledge on this aspect. According to the study, the female $S$. frugiperda laid eggs as clusters, mainly on abaxial surface of the leaf blade near the mid-rib and leaf margin. An egg cluster consisted of an average of $73 \pm 7$ eggs arranged irregularly mainly as a single layer. Egg colour varied from creamy white to light grey 
depending upon egg maturity and the diameter of eggs ranged from $0.38 \mathrm{~mm}$ to $0.55 \mathrm{~mm}$. Spodoptera frugiperda eggs were spherical and resembled a chain of pearls. They were heavily sculptured with vertical and horizontal ridges, and naked, partially covered or fully covered with hairs. Sculpturing of eggs and coverings by hairs should be considered with significance when implementing pest control strategies. The study provides information that is effective for $S$. frugiperda management and may be practical from a farmers' point of view.

\section{ACKNOWLEDGEMENTS}

The authors express their gratitude for the financial assistance, laboratory facilities and technical support provided by the Department of Zoology and Environment Sciences of Faculty of Science, University of Colombo.

\section{REFERENCES}

Agarwala, B.K. and Dixon, A.F.G. (1993). Why do ladybirds lay eggs in clusters? Functional Ecology. 7: 541-548. https://www.jstor.org/stable/2390130

Ahissou, B.R., Sawadogo, W.M., Bokonon-Ganta, A.H., Somda, I. and Verheggen, F. (2021). Integrated pest management options for the fall armyworm Spodoptera frugiperda inWest Africa: Challenges and opportunities. A review. Biotechnologie, Agronomie, Société et Environnement. 25(3): 192-207.

Assefa, F. and Ayalew, D. (2019). Status and control measures of fall armyworm (Spodoptera frugiperda) infestations in maize fields in Ethiopia: A review. Cogent Food and Agriculture. 5: 1-16. https://doi.org/10.1080/23311932.2019.1641902

Azidah, A.A. and Sofian-Azirun, M. (2006). Some aspects on oviposition behavior of Spodoptera exigua (Hubner) (Lepidoptera: Noctuidae). Journal of Entomology. 3(3): 241-247.

Bessera, E.B. and Parra, J.R.P. (2005). Impact of the number of Spodoptera frugiperda egg layers on parasitism by Trichogramma atopovirilia. Scientia Agricola (Piracicaba. Braz.). 62(2): 190193.

Bialozor, A., Perini, C.R., Arnemann, J.A., Pozebon, H., Melo, A.A., Padilha, G., Stacke, R.S., Puntel, L., Drebes, L. and Guedes, J.V.C. (2020). Water in maize whorl enhances the control of Spodoptera frugiperda with insecticides. Pesquisa Agropecuaria Tropical. 50: 1-10. https://doi. org/10.1590/1983-40632020v5059517

Campbell, B.E., Pereira, R.M. and Koehler, P.G. (2016). Complications with controlling insect eggs. In: Insecticides Resistance. IntechOpen. 83-96.

Capinera, J.L. (2000). Fall Armyworm, Spodoptera frugiperda (J. E. Smith) (Insecta: Lepidoptera: Noctuidae). Gainsville, FL: University of Florida Cooperative Extension Service, Institute of Food and Agricultural Sciences, EDIS.

De Groote, H., Kimenju, S.C., Munyua, B., Palmas, S., Kassie, M. and Bruce, A. (2020).Spread and impact of fall armyworm (Spodoptera frugiperda J.E. Smith) in maize production areas of Kenya. Agriculture, Ecosystems and Environment. 292: 1- 10.https://doi.org/10.1016/j. agee.2019.106804 
Dong, H., Zhu, K.H., Zhao, Q., Bai, X.P., Zhou, J.C. and Zhang, L.S. (2021). Morphological defense of the egg mass of Spodoptera frugiperda (Lepidoptera: Noctuidae) affects parasitic capacity and alters behaviors of egg parasitoid wasps. Journal of Asia-Pacific Entomology. 24(3): 671678. https://doi.org/10.1016/j.aspen.2021.05.015

Early, R., Gonzalez-Moreno, P., Murphy, S.T. and Day, R. (2018). Forecasting the global extent of invasion of the cereal pest Spodoptera frugiperda, the fall armyworm. NeoBiota. 40: 25-50. https://doi.org/10.3897/neobiota.40.28165

Hardke, J.T., Lorenz III, G.M. and Leonard, B.R. (2015). Fall armyworm (Lepidoptera: Noctuidae) ecology in southeastern cotton. Journal of Integrated Pest Management. 6(1): 1-8. https://doi. org/10.1093/jipm/pmv009

Harrison, R.D., Thierfelder, C., Baudron, F., Chinwada, P., Midega, C., Schaffner, U. and van den Berg, J. (2019). Agro-ecological options for fall armyworm (Spodoptera frugiperda JE Smith) management: Providing low-cost, smallholder friendly solutions to an invasive pest. Journal of Environmental Management. 243: 318-330. https://doi.org/10.1016/j.jenvman.2019.05.011

Hebert, P.D.N. (1983). Egg dispersal patterns and adult feeding behavior in the Lepidoptera. The Canadian Entomologist. 115(11): 1477-1481.

Hilker, M. and Fatouros, N.E. (2015). Plant responses to insect egg deposition. Annual Review of Entomology. 60: 493-515. https://doi.org/10.1146/annurev-ento-010814-020620

Hinds, W.E. and Dew, J.A. (1915). The grass worm or fall army worm. Vol. 186. The Paragon Press, Agricultural Experiment Station of the Alabama Polytechnic Institute, Auburn, Montgomery, Alabama.

Jaraleño-Teniente, J., Lomeli-Flores, J.R., Rodríguez-Leyva, E., Bujanos-Muñiz, R. and RodríguezRodríguez, S.E. (2020). Egg parasitoids survey of Spodoptera frugiperda (Smith) (Lepidoptera: Noctuidae) in maize and sorghum in Central Mexico. Insects. 11: 157. https://doi:10.3390/ insects 11030157

Junior, A.L.B., Campos, Z.R., Campos, A.R., Filho, W.V.V. and Campos, O.R. (2013). Spodoptera frugiperda (J.E. Smith) (Lepidoptera: Noctuidae) in cotton: vertical distribution of egg masses, effects of adult density and plant age on oviposition behavior. Agricultural Entomology. 80(4): 424-429.

Korycinska, A. (2012). A description of the eggs of seven species of Noctuidae (Lepidoptera) commonly transported by plant trade to the UK, and their separation using stereomicroscopy and scanning electron microscopy. Tijdschrift voor Entomologie. 155: 15-28. https://doi. $\operatorname{org} / 10.1163 / 221194312 X 651391$

Liao, Y.L., Yang, B., Xu, M.F., Lin, W., Wang, D.S., Chen, K.W. and Chen, H.Y. (2019). First report of Telenomus remus parasitizing Spodoptera frugiperda and its field parasitism in southern China. Journal of Hymenoptera Research. 73: 95-102. https://doi.org/10.3897/jhr.73.39136

Luginbill, P. (1928). The fall armyworm. Vol. 34. Department of Agriculture, WashingtonD.C., United States.

Murúa, G. and Virla, E. (2004). Population parameters of Spodoptera frugiperda (Smith) (Lepidoptera: Noctuidae) fed on corn and two predominant grasses in Tucuman (Argentina). Acta Zoológica Mexicana. 20(1): 199-210. 
Murúa, M.G., Vera, M.T., Abraham, S., Juaréz, M.L., Prieto, S., Head, G.P. and Willink, E. (2008). Fitness and mating compatibility of Spodoptera frugiperda (Lepidoptera: Noctuidae) populations from different host plant species and regions in Argentina. Annals of the Entomological Society of America. 101(3): 639-649.

Nagoshi, R.N., Htain, N.N., Boughton, D., Zhang, L., Xiao, Y., Nagoshi, B.Y. and Mota-Sanchez, D. (2020). Southeastern Asia fall armyworms are closely related to populations in Africa and India, consistent with common origin and recent migration. Scientific Reports. 10(1421): 1-10. https://doi.org/10.1038/s41598-020-58249-3

Njuguna, E., Nethononda, P., Maredia, K., Mbabazi, R., Kachapulula, P., Rowe, A. and Ndolo, D. (2021). Experiences and perspectives on Spodoptera frugiperda (Lepidoptera: Noctuidae) management in Sub-Saharan Africa. Journal of Integrated Pest Management. 12(1): 1-9. https://doi:10.1093/jipm/pmab002

Paredes-Sánchez, F.A., Rivera, G., Bocanegra-García, V., Martínez-Padrón, H.Y., BerronesMorales, M., Niño-García, N. and Herrera-Mayorga, V. (2021). Advances in control strategies against Spodoptera frugiperda. A review. Molecules. 26:5587. https://doi.org/10.3390/ molecules26185587

Perera, N., Magamage, M., Kumara, A., Galahitigama, H., Dissanayake, K., Wekumbura, C., Iddamalgoda, P., Siriwardhana, C. and Yapa, P. (2019). Fall armyworm (FAW) epidemic in Sri Lanka: Ratnapura district perspectives. International Journal of Entomological Research. 7(1): 9-18. https://doi.org/10.33687/entomol.007.01.2887

Peterson, A. (1964). Egg types among moths of the Noctuidae (Lepidoptera). Florida Entomologist. 47(2): 71-91.

Santillán-Guayasamín, S., Villacís, A.G., Grijalva, M.J. and Dujardin, J.P. (2017). The modern morphometric approach to identify eggs of Triatominae. Parasites and Vectors. 10(1): 1-10. https://doi.org/10.1186/s13071-017-1982-2

Sisay, B., Simiyu, J., Malusi, P., Likhayo, P., Mendesil, E., Elibariki, N., Wakgari, M., Ayalew, G. and Tefera, T. (2018). First report of the fall armyworm, Spodoptera frugiperda (Lepidoptera: Noctuidae), natural enemies from Africa. Journal of Applied Entomology. 1-5. https://doi. org/10.1111/jen. 12534

Sotelo-Cardona, P., Chuang, W.P., Lin, M.Y., Chiang, M.Y. and Ramasamy, S. (2021). Oviposition preference not necessarily predicts offspring performance in the fall armyworm, Spodoptera frugiperda (Lepidoptera: Noctuidae) on vegeTable 0crops. Scientific Reports. 11:15885. https:// doi.org/10.1038/s41598-021-95399-4

Sparks, A.N. (1979). A review of the biology of the fall armyworm. Florida Entomologist. 62: 82-87.

Stamp, N.E. (1980). Egg deposition patterns in butterflies: Why do some species cluster their eggs rather than deposit them singly? The American Naturalist. 115(3): 367-380.

Storey-Palma, J., Benitez, H.A., Mundaca, E.A. and Vargas, H.A. (2014). Egg laying site selection by a host plant specialist leaf miner moth at two intra-plant levels in the northern Chilean Atacama Desert. Revista Brasileira de Entomologia. 58(3): 280-284. http://dx.doi.org/10.1590/S008556262014000300009 
Tambo, J.A., Day, R.K., Lamontagne-Godwin, J., Silvestri, S., Beseh, P.K., Oppong-Mensah, B., Phiri, N.A. and Mathews, M. (2020). Tackling fall armyworm (Spodoptera frugiperda) outbreak in Africa: an analysis of farmers' control actions. International Journal of Pest Management. 66(4): 298-310. https://doi.org/10.1080/09670874.2019.1646942

Tefera, T., Goftishu, M., Ba, M. and Muniappan, R. (2019). A guide to biological control of fall armyworm in Africa using egg parasitoids. First edition. Nairobi, Kenya. 108pp.

Temerak, S.A. (2006). Role of moth scales remain on the top of egg masses of Spodoptera littoralis and its interference with the performance of the natural bio-product Spinosad. Journal of Entomology. 3(2): 102-107.

Ulmer, B., Gillott, C. and Erlandson, M. (2003). Conspecific eggs and Bertha armyworm, Mamestra configurata (Lepidoptera: Noctuidae), oviposition site selection. Environmental Entomology. 32(3): 529-534.

Vargas-Madríz, H., Bautista-Martínez, N., Vera-Graziano, J., García-Gutiérrez, C. and ChavarínPalacio, C. (2013). Morphometrics of eggs, nymphs, and adults of Bactericera cockerelli (Hemiptera: Triozidae), grown on two varieties of tomato under greenhouse conditions. Florida Entomologist. 71-79. https://doi.org/10.1653/024.096.0110

Wanasinghe, V.K.A.S.M., Chanchala, K.M.G., Karunathilake, A.P., Nikpay, A. and Nugaliyadde, L. (2019). First report of fall army worm; Spodoptera frugiperda (Lepidoptera: Noctuidae) in Sugarcane in Sri Lanka. Proceedings of the International Sugar and Sugarcane Conference, Sri Lanka, pp. 39.

Wijerathna, D.M.I.J., Ranaweera, P.H., Perera, R.N.N., Dissanayake, M.L.M.C. and Kumara, J.B.D.A.P. (2021). Biology and feeding preferences of Spodoptera frugiperda (Lepidoptera: Noctuidae) on maize and selected vegeTable 0crops. The Journal of Agricultural Sciences - Sri Lanka. 16(1): 126-134. http://doi.org/10.4038/jas.v16i1.9190 